\title{
An N-terminal truncation of the ncd motor protein supports diffusional movement of microtubules in motility assays
}

\author{
Rashmi Chandra ${ }^{1, *}$, Sharyn A. Endow ${ }^{1}$ and Edward D. Salmon ${ }^{2}$ \\ ${ }^{1}$ Department of Microbiology, Duke University Medical Center, Durham, North Carolina 27710, USA \\ ${ }^{2}$ Department of Biology, University of North Carolina, Chapel Hill, North Carolina 27599, USA \\ *Author for correspondence
}

\section{SUMMARY}

The nonclaret disjunctional (ncd) protein is a kinesinrelated microtubule motor protein that is encoded at the claret locus in Drosophila and is required for proper chromosome distribution in meiosis and early mitosis. The protein contains a region with $41 \%$ amino acid sequence identity to kinesin heavy chain, but translocates on microtubules with the opposite polarity to kinesin, toward microtubule minus ends. The overall structure of ncd also differs from kinesin heavy chain, in that the proposed motor domain is present at the $\mathrm{C}$ terminus of the molecule instead of the $\mathrm{N}$ terminus, as in kinesin heavy chain. In studies to define the molecular determinants of ncd function, we constructed and expressed a protein with a deletion of the $\mathrm{N}$-terminal 208 amino acids of the non-motor region. Analysis of the truncated protein shows that the protein exhibits microtubule-stimulated $\mathrm{Mg}^{2+}$-ATPase activity and binds microtubules in pelleting assays. In contrast to near fulllength ncd, the truncated protein does not support directional movement of microtubules in in vitro motility assays. Instead, microtubules show nucleotide-sensitive binding to the truncated protein on glass surfaces and bound microtubules exhibit one-dimensional diffusional movement that is constrained to their longitudinal axis. The diffusional movement reveals a weak binding state of the ncd motor that may represent a mechanochemical intermediate in its ATP hydrolysis cycle. If diffusional movement is a characteristic intrinsic to the claret motor, it is likely to be important in the in vivo function of the protein.

Key words: claret microtubule motor protein, minus-end kinesin motor, diffusional movement

\section{INTRODUCTION}

The nonclaret disjunctional (ncd) protein is a recently identified microtubule motor protein that is encoded at the claret locus in Drosophila and is required for proper chromosome distribution in meiosis and mitosis (Yamamoto et al., 1989; Endow et al., 1990; Hatsumi and Endow, 1992a). Antibodies to ncd localize the protein to spindles in Drosophila oocytes and early embryos (Hatsumi and Endow, 1992b), suggesting that ncd is a microtubule motor involved in spindle function in meiosis and early mitosis. In vitro motility assays with bacterially expressed protein showed that ncd is a minus-end-directed microtubule motor protein (Walker et al., 1990; McDonald et al., 1990). The ncd motor generates torque as it moves on microtubules, causing microtubules to rotate as they glide on protein-coated glass surfaces (Walker et al., 1990), and it also crosslinks or bundles microtubules (McDonald et al., 1990; Chandra et al., 1993).

Based on predictions from the deduced amino acid sequence, the 700-amino acid ncd protein (Endow et al., 1990) has an $M_{\mathrm{r}}$ of 77,500 and consists of three domains. The N-terminal 212 amino acids are extremely basic (pI
$=12.2$ ) with a high proline content $(10.4 \%)$. The $\mathrm{N}$ terminus lies adjacent to a central region that consists of heptad repeats of hydrophobic residues and may mediate dimerization of the protein. The C-terminal 320 residues of ncd are $41 \%$ identical in sequence to the mechanochemical domain of kinesin heavy chain (Endow et al., 1990; McDonald and Goldstein, 1990). This domain is present in several recently identified proteins, comprising the kinesin family of related proteins (Endow, 1991; Goldstein, 1991; Endow and Titus, 1992).

In studies directed toward defining the determinants of ncd motor function, we constructed and analyzed an N-terminally truncated protein. The truncated protein, MC1 (Modified Claret 1), is deleted for 208 amino acids of the ncd $\mathrm{N}$ terminus, corresponding to the "tail" of the protein. The MC1 truncated protein exhibits microtubule-stimulated $\mathrm{Mg}^{2+}$-ATPase activity and binds microtubules in pelleting assays. Unexpectedly, microtubules bound by MC1 to glass surfaces in in vitro motility assays exhibit erratic back-andforth movement along their longitudinal axis, instead of the minus-end-directed translocation observed for the near fulllength ncd protein. The behavior of microtubules in motil- 
ity assays suggests that the $\mathrm{MC} 1$ truncated protein represents a weak binding state of the ncd motor. This weak binding state may be important in the mechanochemical function of the ncd motor protein.

\section{MATERIALS AND METHODS}

\section{Construction of MC1}

MC1 was constructed from the previously reported $\mathrm{pET} / \mathrm{ncd}$ plasmid (Walker et al., 1990) by partial digestion with BamHI followed by complete digestion with $A f I I I$. The restriction enzymedigested plasmid was repaired with the Klenow fragment of DNA polymerase I, the restriction enzyme digestion products were separated by gel electrophoresis, and a fragment of the predicted size $(\sim 6.1 \mathrm{~kb})$ was excised and the ends ligated. The pET3/MC1 construct was transformed into BL21(DE3) host cells carrying the bacteriophage T7 RNA polymerase gene under the control of the lacUV5 promotor (Studier et al., 1990). DNA sequence analysis was carried out on chloramphenicol-amplified minipreps of the $\mathrm{pET} / \mathrm{MC} 1$ plasmid, using the dideoxy chain termination method (Sanger et al., 1977).

\section{MC1 expression and purification}

Cells were grown at $37^{\circ} \mathrm{C}$ to a density of $A_{550}=0.7$ and induced by addition of isopropyl $\beta$-D-thiogalactoside (IPTG) to $0.4 \mathrm{mM}$, followed by rapid shaking for $5 \mathrm{~h}$ at $24^{\circ} \mathrm{C}$. Packed, induced cells were suspended in $3.5 \mathrm{ml} / \mathrm{g}$ wet weight of $\mathrm{AB}$ (20 mM Pipes, $\mathrm{pH}$ $6.9,1 \mathrm{mM} \mathrm{MgCl} 2,1 \mathrm{mM}$ EGTA, $0.5 \mathrm{mM}$ DTT) and treated with $0.1 \mathrm{mg} / \mathrm{ml}$ lysozyme + protease inhibitors for $30 \mathrm{~min}$ on ice. Following 2 cycles of freeze/thaw, lysates were adjusted to $40 \mu \mathrm{g} / \mathrm{ml}$ DNase I and $10 \mathrm{mM} \mathrm{MgCl} 2$, kept for $10 \mathrm{~min}$ on ice, and then centrifuged at $27,000 \mathrm{~g}$ for $20 \mathrm{~min}$. Approximately $40 \%$ of the induced protein was recovered in the soluble fraction. The supernatant was passed over a $1 \mathrm{ml} \mathrm{S}$-Sepharose column (Pharmacia) in PB $\left(10 \mathrm{mM} \mathrm{NaPO}, \mathrm{pH} 7.4,1 \mathrm{mM} \mathrm{MgCl}_{2}, 1 \mathrm{mM}\right.$ EGTA, $1 \mathrm{mM}$ DTT) and protein was eluted using $0.1 \mathrm{M}-0.5 \mathrm{M}$ steps of $\mathrm{NaCl}$ in $\mathrm{PB}$. The $\mathrm{MC} 1$ protein eluted at $0.1-0.2 \mathrm{M} \mathrm{NaCl}$. The eluted protein was dialyzed against $\mathrm{PB}$ and stored frozen at $-70^{\circ} \mathrm{C}$. Purification of the bacterially expressed $\mathrm{MC} 1$ protein was monitored by cross-reactivity on immunoblots with an antibody directed against the conserved HIPYRESKLT motif (a gift from K. Sawin) present in the motor domain of the kinesin-related proteins (Endow, 1991; Sawin et al., 1992; Cole et al., 1992).

\section{ATPase assays}

The protein concentration of purified $\mathrm{MC} 1$ was determined using the Bradford colorimetric assay. ATPase assays were performed at $24^{\circ} \mathrm{C}$ using modifications of published methods (Cohn et al., 1987; Wagner et al., 1989). $300 \mu 1$ reaction mixtures contained $20 \mu \mathrm{g} / \mathrm{ml} \mathrm{MC} 1+4 \mathrm{mM} \mathrm{Mg}{ }^{2+}-\left[\gamma^{3}{ }^{32} \mathrm{P}\right] \mathrm{ATP}(5,000-35,000$ cts per $\mathrm{min} / \mathrm{nmole}$ ATP) \pm taxol-stabilized microtubules (tubulin concentration $=1 \mathrm{mg} / \mathrm{ml}$ ) in $15 \mathrm{mM}$ imidazole, $\mathrm{pH} 7.0,2 \mathrm{mM} \mathrm{MgCl}$, $1 \mathrm{mM}$ EGTA, $1 \mathrm{mM}$ DTT. $2 \mu \mathrm{l}$ and $4 \mu \mathrm{l}$ of the reaction mix were counted in scintillation fluid to determine ATP specific activity. $40 \mu \mathrm{l}$ samples were withdrawn at $0,2,5,10,20,40$ and $60 \mathrm{~min}$ into microfuge tubes containing $0.76 \mathrm{ml}$ of $5 \%$ activated charcoal (Norit A, Aldrich) suspended in $50 \mathrm{mM} \mathrm{NaH} \mathrm{PO}_{4}$ (Higashijima et al., 1987). The charcoal mixes were kept on ice for $15 \mathrm{~min}$, tubes were centrifuged for $5 \mathrm{~min}$ at $15,600 \mathrm{~g}$, and the supernatants were removed and recentrifuged to remove charcoal particles. The activated charcoal binds unhydrolyzed ATP but not released $\mathrm{P}_{\mathrm{i}}$, which remains in the supernatant. $150 \mu \mathrm{l}$ and $300 \mu \mathrm{l}$ of the final supernatants were taken for scintillation counting. $<2 \%$ of the total counts were present as $P_{i}$ in samples at the 0 min timepoints.

The effects of vanadate and AMP-PNP on MC1 ATPase activ- ity were tested by incubating $100 \mu \mathrm{l}$ reaction mixes containing 10 $\mu \mathrm{g} / \mathrm{ml} \mathrm{MC1}$ protein $+8 \mathrm{nM} \mathrm{Mg}{ }^{2+}-\left[\gamma^{-32} \mathrm{P}\right]$ ATP $\left(4 \times 10^{6}\right.$ cts per $\mathrm{min} / \mathrm{pmole})+$ taxol-stabilized microtubules (tubulin concentration $=1 \mathrm{mg} / \mathrm{ml})+$ vanadate $(0,100 \mu \mathrm{M}$ or $200 \mu \mathrm{M})$ or AMP-PNP $(0$, $0.5 \mathrm{mM}, 1 \mathrm{mM}, 2 \mathrm{mM}$ or $5 \mathrm{mM}$ ) in $15 \mathrm{mM}$ imidazole, $\mathrm{pH} \mathrm{7.0,}$ $2 \mathrm{mM} \mathrm{MgCl}_{2}, 1 \mathrm{mM}$ EGTA, $1 \mathrm{mM}$ DTT for $20 \mathrm{~min}$ at $24^{\circ} \mathrm{C} .2$ $\mu \mathrm{l}$ and $4 \mu \mathrm{l}$ of each reaction mix were counted to determine ATP specific activity and $40 \mu \mathrm{l}$ samples were withdrawn at 0 and 20 min to determine $P_{i}$ released, as described above. $P_{i}$ released for each concentration of vanadate or AMP-PNP was expressed as percentage of $\mathrm{P}_{\mathrm{i}}$ released in mixes containing $\mathrm{MC1}$ protein + microtubules with no added inhibitor.

Taxol-stabilized microtubules were assembled from phosphocellulose-purified porcine brain tubulin, as described previously (Walker et al., 1988). ATPase assays in the presence of taxol-stabilized microtubules contained $\sim 0.2 \mathrm{mM} \mathrm{Mg}^{2+} \mathrm{GTP}_{\mathrm{G}}$ from the microtubule mix.

\section{Microtubule pelleting assays}

Microtubule pelleting assays were performed by incubating 50 $\mu \mathrm{g} / \mathrm{ml}$ purified $\mathrm{MC1}$ protein with taxol-stabilized microtubules (tubulin concentration $=0.5 \mathrm{mg} / \mathrm{ml})$ in $\mathrm{AB}+\mathrm{GT}(\mathrm{AB}+0.1 \mathrm{mM}$ $\mathrm{Mg}^{2+}-\mathrm{GTP}+10 \mu \mathrm{M}$ taxol) in a volume of $100 \mu \mathrm{l}$. Binding of $\mathrm{MC} 1$ to microtubules was also tested in $\mathrm{AB}+\mathrm{GT}$ containing $5 \mathrm{mM}$ $\mathrm{Mg}^{2+}-\mathrm{ATP} \pm 0.1 \mathrm{M} \mathrm{NaCl}$, or $5 \mathrm{mM}$ AMP-PNP. Control reactions in $\mathrm{AB}+\mathrm{GT}$ contained $\mathrm{MC} 1$ protein $+5 \mathrm{mM} \mathrm{Mg}^{2+}$-ATP with no microtubules, or microtubules $+5 \mathrm{mM} \mathrm{Mg}^{2+}$-ATP with no added MC1 protein. Assays containing microtubules had an additional $\sim 0.1 \mathrm{mM} \mathrm{Mg}{ }^{2+}$-GTP from the stabilized microtubule mix. After incubation for $30 \mathrm{~min}$ at room temperature, reaction mixes were centrifuged at $100,000 \mathrm{~g}$ for $20 \mathrm{~min}$ at $22^{\circ} \mathrm{C}$. The supernatant was transferred to a tube containing $20 \mu \mathrm{l}$ of $5 \times$ SDS loading buffer and the pellet was resuspended in $120 \mu \mathrm{l}$ of $1 \times$ SDS loading buffer. Equal volumes of the pellet and supernatant were analyzed by SDS-polyacrylamide gel electrophoresis (SDS-PAGE). Release of $\mathrm{MC} 1$ protein from the AMP-PNP pellet by $\mathrm{Mg}^{2+}$-ATP was determined by washing the pellet with $\mathrm{AB}+\mathrm{GT}$ and resuspending the pellet in $10 \mathrm{mM} \mathrm{Mg}^{2+}$-ATP in $\mathrm{AB}+\mathrm{GT}$ for $20 \mathrm{~min}$. The mix was centrifuged again at $100,000 \mathrm{~g}$, and the pellet and supernatant analyzed as above. Gels were stained with Coomassie Blue and wet gels were scanned using an LKB Ultroscan XL Enhanced Laser Densitometer to determine relative amounts of $\mathrm{MC} 1$ protein in the pellet and supernatant.

\section{Microtubule motility assays}

MC1 protein for motility assays was purified as described above, or prepared by precipitation of protein from the $27,000 \mathrm{~g}$ supernatant with ammonium sulfate at $40 \%$ of saturation, followed by dialysis of the redissolved protein against PB. Motility assays were carried out at $\sim 22^{\circ} \mathrm{C}$ and were routinely performed by mixing sequentially $5 \mu \mathrm{l}$ of protein in $\mathrm{PB}, 1.6 \mu \mathrm{l}$ of taxol-stabilized microtubules (tubulin concentration $=1 \mathrm{mg} / \mathrm{ml}$ ), $0.9 \mu \mathrm{l}$ of $50 \mathrm{mM} \mathrm{Mg}^{2+}$ ATP and $1.5 \mu \mathrm{l}$ of $6 \times$ salt solution (70 mM Pipes, $\mathrm{pH} 6.9,480$ $\mathrm{mM} \mathrm{NaCl}, 1.4 \mathrm{mM}$ EGTA, $0.7 \mathrm{mM} \mathrm{MgSO}$, $30 \mathrm{mM} \mathrm{MgCl}_{2}, 4.8$ mM DTT) on a clean glass coverslip. The coverslip was inverted onto a glass slide, the edges were sealed, and movement was observed using video-enhanced differential interference contrast (VE-DIC) microscopy (Walker et al., 1990). Motility assays with vanadate contained no added $\mathrm{Mg}^{2+}$-ATP, and assays with AMPPNP contained no added $\mathrm{Mg}^{2+}$-ATP or $6 \times$ salts. Motility assays contained $\sim 0.2 \mathrm{mM} \mathrm{Mg}^{2+}$-GTP from the stabilized microtubule mix.

\section{Data analysis}

VE-DIC images were recorded onto a Panasonic TQ-2028F OMDR (optical memory disc recorder) at video rates of 30 
frames/sec. The $\mathrm{x}, \mathrm{y}$ coordinate position of microtubule ends (accuracy $=100 \mathrm{~nm} /$ pixel) was entered into an IBM AT computer using a mouse-driven video-cursor (Walker et al., 1988) overlaid on images played back from the OMDR at ten-frame $(0.33 \mathrm{sec})$ intervals over a period of $120 \mathrm{sec}$ (360 data points). Analysis of diffusional motion was carried out as described in Vale et al. (1989) and Qian et al. (1991), based on the conceptual analysis of Berg (1983). A program written in Microsoft Quick Basic was used to generate displacement histograms and to calculate mean displacement and mean square displacement as a function of sampling time interval.

\section{RESULTS}

\section{Expression of MC1}

The N-terminally truncated ncd protein, MC1, is expressed in bacteria as a fusion protein containing 11 amino acids of bacteriophage T7 S10 protein, 2 linker amino acids and 492 residues of ncd (Fig. 1). The MC1 protein begins at residue 209 of the predicted 700-amino acid, full-length claret protein (Endow et al., 1990). The bacterially expressed protein cross-reacts with an antibody directed against the conserved HIPYRESKLT motif present in the motor domain, indicating that the protein is in-frame (Fig. 2). DNA sequence analysis of the MC1 construct confirmed that there were no base changes in the promoter, the S10 or ncd sequences, and that the S10/ncd fusion was in-frame.

The MC1 protein was purified to $>95 \%$ homogeneity (Fig. 2) by passing an induced bacterial cell lysate over SSepharose. The MC1 protein binds to the resin and elutes at $0.1-0.2 \mathrm{M} \mathrm{NaCl}$. The purified protein is active in ATPase assays, and binds microtubules in pelleting assays and in in vitro motility assays (see below).

\section{MC1 is a microtubule-stimulated $\mathbf{M g}^{2+}$-ATPase}

The $\mathrm{Mg}^{2+}$-ATPase activity of purified MC1 was determined in the presence and absence of microtubules (Table 1). MC1 showed a $k_{\text {cat }}$ of $\sim 0.05 \mathrm{~s}^{-1}$ in the absence of microtubules. On addition of microtubules, the $k_{\text {cat }}$ of the $\mathrm{MC} 1 \mathrm{Mg}^{2+}$ ATPase was $\sim 0.4 \mathrm{~s}^{-1}$, showing a stimulation of 8 -fold over

\begin{tabular}{l|l|l|l}
\multicolumn{2}{c}{ Basic region } & \multicolumn{2}{c}{ Motor domain } \\
ncd $\mathrm{N}$ & & &
\end{tabular}

$\mathrm{pET} / \mathrm{ncd}$

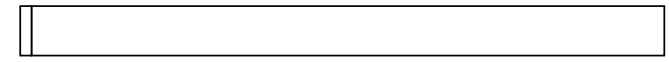

$\mathrm{pET} / \mathrm{MC1}$

Fig. 1. MC1 protein. Full-length ncd, near full-length pET/ncd and $\mathrm{pET} / \mathrm{MC} 1$ proteins are shown. MC1 encodes a truncated protein beginning at residue 209 of the full-length ncd protein. The box at the $\mathrm{N}$ terminus of the $\mathrm{pET} / \mathrm{ncd}$ and $\mathrm{pET} / \mathrm{MC} 1$ proteins indicates the 11 amino acids of the bacteriophage T7 S10 protein and 3 or 2, respectively, linker amino acids. The basic region extends from residues 1-212; the motor domain corresponds to amino acids 349-671 (Endow et al., 1990). The bar represents the HIPYRESKLT motif at amino acids 619-628. the basal level and demonstrating that MC1 is a microtubule-stimulated $\mathrm{Mg}^{2+}$-ATPase. The release of $\mathrm{P}_{\mathrm{i}}$ catalyzed by $\mathrm{MC} 1$ was linear for the $60 \mathrm{~min}$ of the assay, indicating that the MC1 $\mathrm{Mg}^{2+}$-ATPase activity is relatively stable at room temperature. Stimulation of the basal $\mathrm{Mg}^{2+}$-ATPase activity of MC1 was observed in the presence of microtubules (tubulin concentration $=1 \mathrm{mg} / \mathrm{ml}$ ), but not in the

\section{Coomassie Blue}

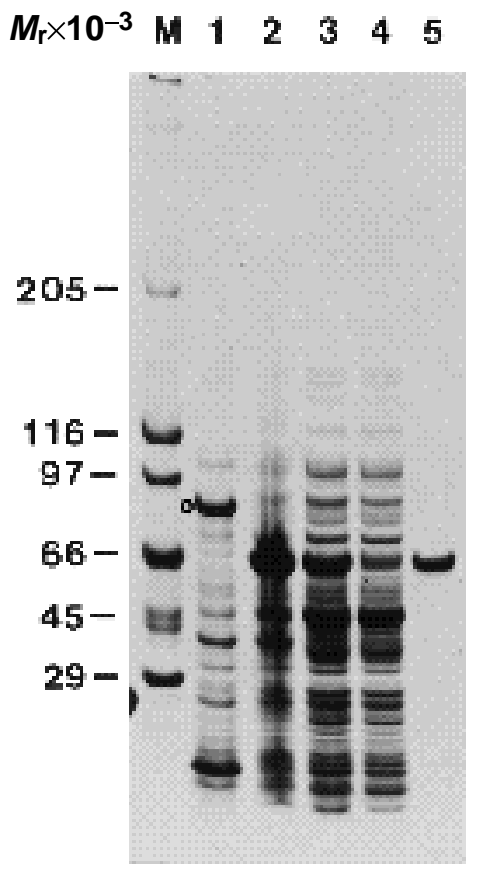

Immunoblot

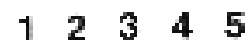

Fig. 2. Expression of MC1 in bacterial cells. 3.5\%-17\% exponential gradient polyacrylamide gel stained with Coomassie Blue (left panel) and corresponding immunoblot (right panel) reacted with anti-HIPYRESKLT antibody. Lanes: M, molecular mass markers; 1 , bacterial cell lysate of near full-length ncd $\left(M_{\mathrm{r}}\right.$ $\sim 74,400)\left({ }^{\circ}\right)$ after $4 \mathrm{~h}$ induction at $24^{\circ} \mathrm{C} ; 2$, bacterial cell lysate of $\mathrm{MC} 1$ after $5 \mathrm{~h}$ induction at $24^{\circ} \mathrm{C} ; 3$, S-Sepharose column load; 4 , S-Sepharose column flowthrough; 5 , pooled fractions eluted with $0.1 \mathrm{M} \mathrm{NaCl}$.

Table 1. $\mathrm{Mg}^{2+}$-ATPase activity of $\mathrm{MC1}$

\begin{tabular}{|c|c|c|c|c|}
\hline \multirow[b]{2}{*}{ MC1 } & \multicolumn{3}{|c|}{$\begin{array}{c}\mathrm{Mg}^{2+}-\mathrm{ATPase} \text { activity } \\
\left(\mathrm{s}^{-1}\right)\end{array}$} & \multirow[b]{2}{*}{$\begin{array}{l}\text { Diffusional } \\
\text { movement }\end{array}$} \\
\hline & Without MT & With MT & $\begin{array}{c}\text { Fold } \\
\text { stimulation }\end{array}$ & \\
\hline 1 & 0.05 & 0.4 & 8 & + \\
\hline 2 & 0.05 & 0.4 & 8 & + \\
\hline $2+0.2 \mathrm{mM}$ vanadate & & $0.4^{*}$ & & + \\
\hline $2+5 \mathrm{mM}$ AMP-PNP & & $0.06^{*}$ & & - \\
\hline \multicolumn{5}{|c|}{ 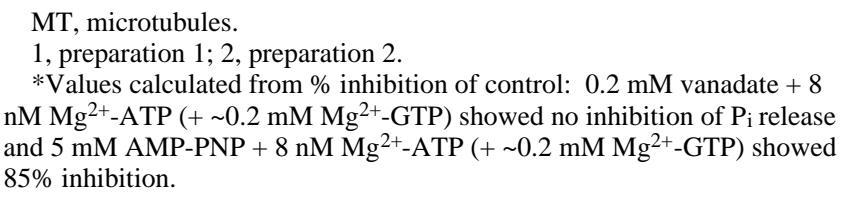 } \\
\hline
\end{tabular}




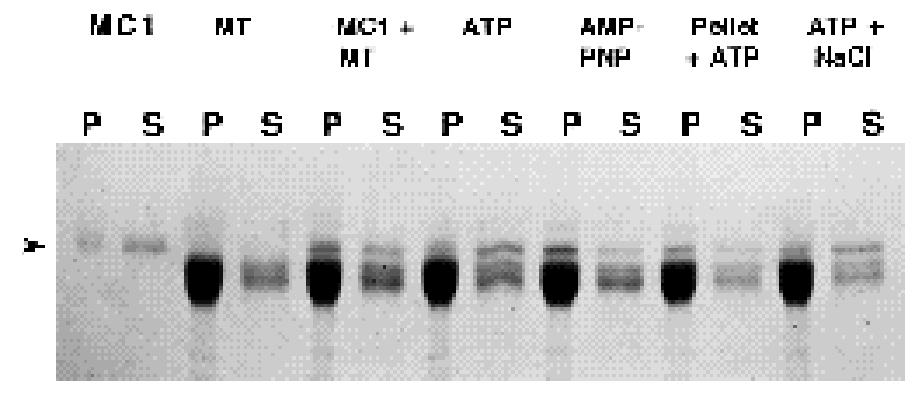

Fig. 3. Microtubule pelleting assays. Binding of MC1 protein to microtubules was determined by incubating purified protein with taxol-stabilized microtubules and centrifugation of reaction mixes, followed by separation of proteins in the pellet and supernatant by SDS-PAGE. Assays were carried out in the presence or absence of $5 \mathrm{mM} \mathrm{Mg}^{2+}$-ATP $\pm 0.1 \mathrm{M} \mathrm{NaCl}$, or presence of $5 \mathrm{mM}$ AMP-PNP. Control mixes contained $\mathrm{MC} 1$ protein without microtubules, or microtubules without MC1 protein. The region of a Coomassie Blue-stained gel containing the MC1 protein band (arrow) and band(s) of tubulin is shown. P, pellet; S, supernatant; MT, microtubules.

presence of $1 \mathrm{mg} / \mathrm{ml}$ tubulin $+100 \mathrm{mM}$ nocodazole. Control experiments with microtubules without added $\mathrm{MC1}$ protein showed background levels of released $\mathrm{P}_{\mathrm{i}}$.

The rate of microtubule-stimulated $\mathrm{Mg}^{2+}$-ATP hydrolysis catalyzed by $\mathrm{MC} 1$ was not affected in assays containing $0.1 \mathrm{mM}$ or $0.2 \mathrm{mM}$ vanadate $+8 \mathrm{nM} \mathrm{Mg}^{2+}$-ATP, but showed $\sim 50 \%$ inhibition in $1.5 \mathrm{mM}$ AMP-PNP $+8 \mathrm{nM}$ $\mathrm{Mg}^{2+}$-ATP and $\sim 85 \%$ inhibition in $5 \mathrm{mM}$ AMP-PNP +8 $\mathrm{nM} \mathrm{Mg}{ }^{2+}$-ATP (Table 1). These assays also contained $\sim 0.2$ $\mathrm{mM} \mathrm{Mg}{ }^{2+}$-GTP from the taxol-stabilized microtubules.

\section{MC1 binds microtubules in pelleting assays}

Binding of purified MC1 protein to microtubules was tested in the absence of added ATP, and in the presence of $5 \mathrm{mM}$ $\mathrm{Mg}^{2+}$-ATP $\pm 0.1 \mathrm{M} \mathrm{NaCl}$ and $5 \mathrm{mM}$ AMP-PNP (Fig. 3). Release of bound $\mathrm{MC} 1$ protein by $10 \mathrm{mM} \mathrm{Mg}^{2+}$-ATP from the AMP-PNP pellet was also determined. Assays with microtubules contained $\sim 0.2 \mathrm{mM} \mathrm{Mg}^{2+}$-GTP from the buffer and taxol-stabilized microtubules, while protein-only mixes contained $0.1 \mathrm{mM} \mathrm{Mg}{ }^{2+}-\mathrm{GTP}$ from the buffer. A fraction of the purified $\mathrm{MC} 1$ protein $(\sim 25 \%)$ pellets in the absence of microtubules, presumably due to protein aggregation. The fraction of protein that pellets in the absence of microtubules was determined by densitometer scans of wet Coomassie Blue-stained gels, and subtracted from the protein pelleted under each condition tested. Estimated protein amounts were also corrected for differences in gel-lane width. Results indicate that $\sim 60 \%$ of the protein pellets with microtubules in the absence of added ATP, compared with $\sim 25 \%$ in the presence of $5 \mathrm{mM} \mathrm{Mg}^{2+}-\mathrm{ATP} \pm 0.1 \mathrm{M} \mathrm{NaCl}$.

Fig. 4. Differential interference contrast images of a $2.4 \mu \mathrm{m}$ long microtubule showing back-and-forth longitudinal movement on a glass surface coated with MC1. The maximal horizontal displacements are shown in the top 5 panels. Longitudinal motion of the microtubule in other orientations is represented in the bottom 3 panels. The position of a stationary point in the field is indicated by an arrow and the time of each frame in seconds is shown in the upper right corner.
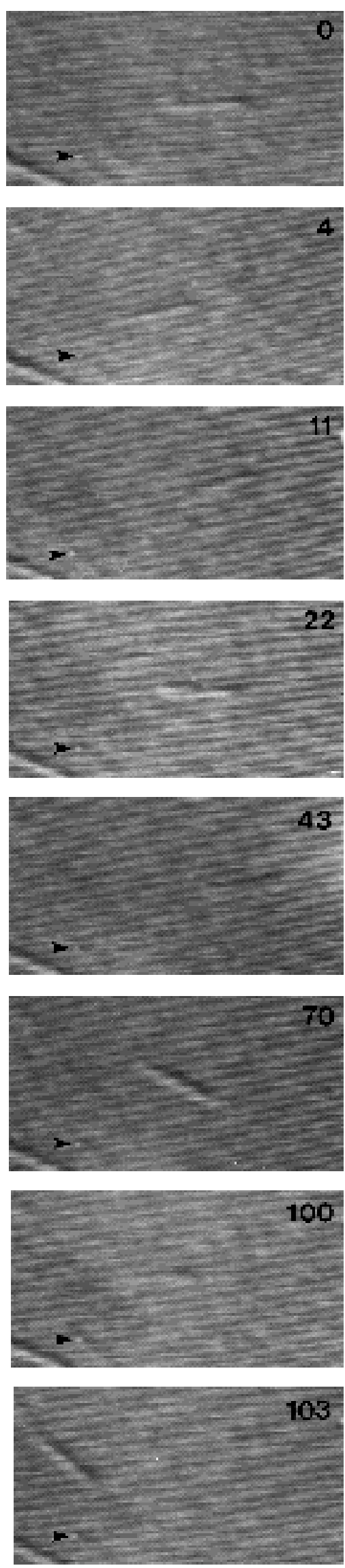
Addition of $5 \mathrm{mM}$ AMP-PNP instead of $\mathrm{Mg}^{2+}$-ATP caused $\sim 70 \%$ of the MC1 protein to pellet with microtubules and $\sim 50 \%$ of the bound protein could be released by resuspension of the AMP-PNP pellet in $10 \mathrm{mM} \mathrm{Mg} \mathrm{Mg}^{2+}$ ATP.

The behavior of the MC1 protein in the solution-pelleting assays is similar to that of kinesin heavy chain (Yang et al., 1989): the MC1 motor protein binds weakly to microtubules in the presence of $\mathrm{Mg}^{2+}$-ATP and remains largely in the supernatant, but binds tightly and pellets with microtubules in the presence of AMP-PNP. In the absence of $\mathrm{Mg}^{2+}$-ATP (presence of $\sim 0.2 \mathrm{mM} \mathrm{Mg}^{2+}-\mathrm{GTP}$ ), $\mathrm{MC} 1$ is present both in the supernatant and pellet, indicating a stronger binding to microtubules than in the presence of $\mathrm{Mg}^{2+}-\mathrm{ATP}$ but a weaker binding than with AMP-PNP. The MC1 motor protein therefore shows nucleotide-sensitive binding to microtubules in solution.

\section{Analysis of movement of microtubules bound to MC1 on glass surfaces}

In vitro motility assays (Walker et al., 1990) were carried out at $\sim 22^{\circ} \mathrm{C}$, using either purified $\mathrm{MC} 1$ protein or lysates enriched in the MC1 protein, and showed efficient binding of taxol-stabilized microtubules to glass coverslips in the presence of $5 \mathrm{mM} \mathrm{Mg}^{2+}$-ATP. Unexpectedly, bound microtubules did not exhibit unidirectional movement, but either appeared stationary on the glass surface or moved erratically back and forth along their longitudinal axis (Fig. 4). Most microtubules of $>15 \mu \mathrm{m}$ appeared stationary, but more than $95 \%$ of microtubules $\leq 4.5 \mu \mathrm{m}$ exhibited rapid, erratic back-and-forth movement along the longitudinal axis of the microtubule. Microtubules of $<\sim 3 \mu \mathrm{m}$ wandered many $\mu \mathrm{m}$ by "runs" of irregular movement in one direction with occasional reorientation (MT7 in Fig. 5A). The paths of these microtubules are typical of the classical one-dimensional "drunken walk" of random Brownian motion (Berg, 1983). The back-and-forth movements of microtubules $>\sim 3 \mu \mathrm{m}$ rarely deviated from the initial direction, and the "drunken walk" of these microtubules persisted along a straight line (MT8 in Fig. 5A).

A detailed analysis of the back-and-forth movement of 14 microtubules was carried out by analyzing the position of microtubule ends at successive intervals of $0.33 \mathrm{~s}$ from data recorded on an OMDR. As an example, the mean square displacement for movement of MT8 along its longitudinal and lateral axes is shown as a function of the time interval between position measurements in Fig. 5B. The mean net longitudinal displacement for MT8 (1.8 nm in a $0.33 \mathrm{~s}$ interval) is much smaller than the root mean square displacement $(240 \mathrm{~nm})$. The magnitude of longitudinal mean square displacement of MT8 increased linearly with the length of the time interval of measurement (Fig. 5B), as predicted for one-dimensional random Brownian motion. The diffusion coefficients, $D_{\text {longitudinal }}=0.063 \mu \mathrm{m}^{2} / \mathrm{s}$ and $D_{\text {lateral }}=0.0018 \mu \mathrm{m}^{2} / \mathrm{s}$, are equivalent to the slopes of the linear regression lines in Fig. 5B divided by 2. Histograms of the net displacements measured at $0.33 \mathrm{~s}$ intervals approximated Gaussian distributions centered around zero displacement (Fig. 5C), indicating that the back-and-forth movement of the microtubule occurred randomly and without a directional bias. Analysis of 13 other microtubules
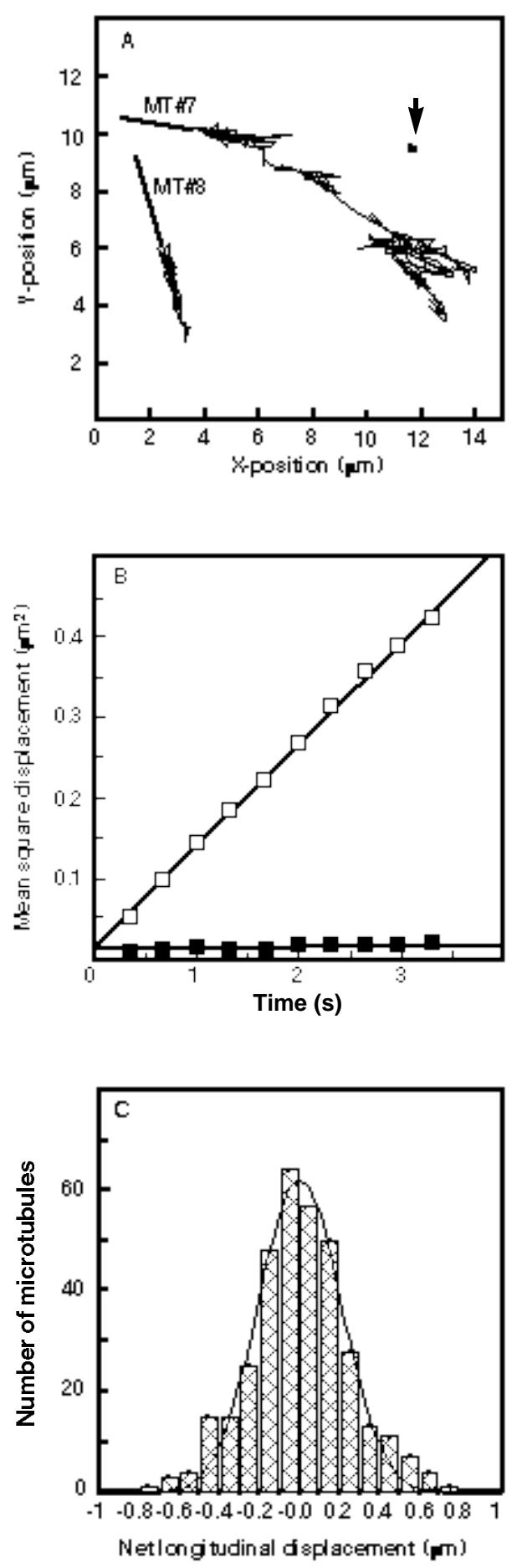

Fig. 5. Detailed motion analysis of microtubules bound by MC1. (A) Longitudinal diffusion exhibited by two short microtubules, MT\#7 $(2.6 \mu \mathrm{m})$ and MT\#8 $(3.5 \mu \mathrm{m})$, and the measured position of a stationary particle (arrow) on the glass surface. The paths of one end of each microtubule are plotted. (B) Mean square displacement of MT\#8 along its longitudinal and lateral axes as a function of time. $\square$, Longitudinal axis; $\boldsymbol{\square}$, lateral axis. Time intervals were multiples of $0.33 \mathrm{~s}$, and ranged from 0.33 to $3.33 \mathrm{~s}$. (C) Histogram of the $0.33 \mathrm{~s}$ longitudinal movements of the end of MT8. The Gaussian curve was generated using the longitudinal diffusion coefficient, $D_{\text {longitudinal }}=0.063 \mu \mathrm{m}^{2} / \mathrm{s}$, obtained as described in the text and scaled to the data by a least squares fit. 


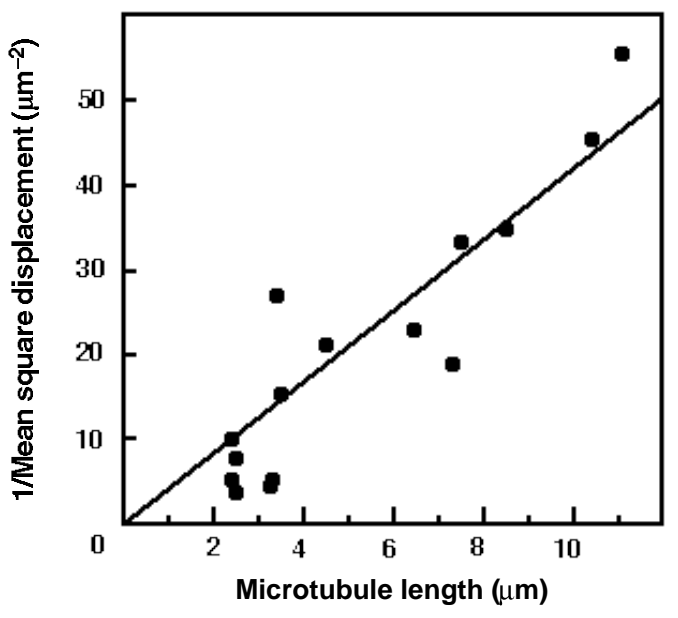

Fig. 6. Reciprocal of the mean square longitudinal + lateral displacement as a function of microtubule length. A least squares line was generated through the origin. Diffusion coefficients were determined for 14 microtubules.

gave similar results. Finally, the reciprocal of the mean square displacements increased approximately linearly with microtubule length (Fig. 6). The "sticking" of longer microtubules limited the diffusional motion analysis to microtubules of less than $\sim 12 \mu \mathrm{m}$ in length.

These results indicate that microtubules bound to $\mathrm{MC} 1$ on glass surfaces exhibit thermally-driven Brownian motion along their longitudinal axis (Berg, 1983; Vale et al., 1989). Repetitive measurements of the center of a stationary particle (Fig. 5A) gave a mean net longitudinal + lateral displacement of $0.39 \mathrm{~nm}$ and a root mean square displacement of $60 \mathrm{~nm}$ for any interval between measured points, indicating that there was little drift during the course of measurement. Furthermore, repetitive measurements of a stationary particle or the ends of "stuck" microtubules yielded diffusion coefficients of $\leq 0.00065 \mu \mathrm{m}^{2} / \mathrm{s}$ from plots of mean square displacement versus time interval.

\section{Dependence of diffusional movement of MC1- bound microtubules on nucleotide and salt}

Microtubules bound to MC1-coated coverslips showed active diffusional movement in the presence of $5 \mathrm{mM} \mathrm{Mg}^{2+}$ ATP. In the absence of added $\mathrm{Mg}^{2+}$-ATP, diffusional movement of bound microtubules could also be observed, but was less active. The concentration of $\mathrm{Mg}^{2+}$-GTP present in the minus- $\mathrm{Mg}^{2+}$-ATP assays was $\sim 0.2 \mathrm{mM}$, and derived from the taxol-stabilized microtubule mix. No added $\mathrm{Mg}^{2+}$ ATP and depletion of $\mathrm{Mg}^{2+}$-GTP by repeated dilution and pelleting of taxol-stabilized microtubules resulted in efficient binding, but reduced diffusional movement, of microtubules attached to MC1-coated glass.

Random diffusional movement of microtubules was observed in the presence of 50-200 $\mu \mathrm{m}$ vanadate with no added $\mathrm{Mg}^{2+}-$ ATP, but $5 \mathrm{mM}$ AMP-PNP with no added $\mathrm{Mg}^{2+}$-ATP or $\mathrm{NaCl}$ caused microtubules in active MC1 protein preparations to become firmly bound to the coverslip and stopped movement of all but the smallest microtubules of $<\sim 1.3 \mu \mathrm{m}$.

Binding of microtubules to MC1-coated glass surfaces in motility assays was sensitive to the concentration of $\mathrm{NaCl}$ present. Microtubules attached to the $\mathrm{MC} 1$ protein on the glass surface and showed diffusional movement in $0-0.1 \mathrm{M}$ $\mathrm{NaCl}+5 \mathrm{mM} \mathrm{Mg}^{2+}$-ATP. For some preparations of MC1, diffusional movement of bound microtubules was enhanced by addition of a $6 \times$ salts solution (see Materials and Methods) that resulted in a $\mathrm{NaCl}$ concentration of $80 \mathrm{mM}$, compared to assays without $6 \times$ salts. However, assays carried out in $0.14 \mathrm{M} \mathrm{NaCl}+5 \mathrm{mM} \mathrm{Mg}^{2+}$-ATP showed a greatly reduced number of microtubules attached along their entire length, and $>0.17 \mathrm{M} \mathrm{NaCl}+5 \mathrm{mM} \mathrm{Mg}^{2+}$-ATP resulted in no bound microtubules.

\section{DISCUSSION}

The claret motor, or ncd, is a kinesin-related microtubule motor protein that has been demonstrated in previous studies (Walker et al., 1990; McDonald et al., 1990) to translocate toward the minus ends of microtubules, in the opposite direction to kinesin. Here we report that deletion of the ncd $\mathrm{N}$ terminus, or non-motor region, results in a protein that exhibits microtubule-stimulated $\mathrm{Mg}^{2+}$-ATPase activity and nucleotide-sensitive binding to microtubules in pelleting assays, but no longer supports directional gliding of microtubules in in vitro motility assays. Instead, microtubules attached to the truncated $\mathrm{MC} 1$ protein on glass surfaces show random diffusional movement that is constrained to the longitudinal axis of the microtubule.

Longitudinal diffusional movement of microtubules bound to a motor protein has previously been reported for only one molecular motor protein, the single-headed $\beta$-IC subunit of axonemal dynein (Vale et al., 1989). The motor properties of $\mathrm{MC} 1$ resemble those of the $\beta$-IC subunit of dynein in the presence of ADP, or ATP and vanadate: movement was sensitive to salt and constrained to the longitudinal axis of the microtubule, net displacement approximated a Gaussian distribution, and mean square displacement increased linearly with measurement interval and was inversely dependent on microtubule length. The one-dimensional diffusional movement of microtubules bound to the $\beta$-IC dynein motor has been interpreted to represent a weak binding state that may be important in motor function (Vale et al., 1989; Vale and Oosawa, 1990). Diffusional movement has not, thus far, been reported for any other molecular motor protein. This work is the first report of a diffusional weak binding state for a member of the kinesin family of proteins.

MC1 attached to a glass surface binds to microtubules either weakly or strongly, depending on the nucleotide present, and the presence or absence of $\mathrm{NaCl}$. Active diffusional movement of microtubules is observed in the presence of $\mathrm{Mg}^{2+}$-ATP, consistent with the idea that the $\mathrm{Mg}^{2+}$-ATP-bound state is a weak binding state. In the absence of added nucleotide triphosphate, microtubules bind to the motor protein on the glass surface and show diffusional movement, but the movement is less active than 
in the presence of $\mathrm{Mg}^{2+}-\mathrm{ATP}$. A weak binding state, characterized by diffusional movement of bound microtubules, can therefore be achieved by addition of $\mathrm{Mg}^{2+}-\mathrm{ATP}$ to the motor, and is enhanced by the presence of $\mathrm{NaCl}$. In the presence of the nonhydrolyzable ATP analogue, AMP-PNP, and absence of $\mathrm{NaCl}$, microtubules are tightly bound and, except for microtubules $<1.3 \mu \mathrm{m}$, do not show diffusional movement.

The MC1 protein shows microtubule-stimulated $\mathrm{Mg}^{2+}$ ATPase activity in solution; however, the diffusional movement of bound microtubules is probably not dependent on the ability of the motor to hydrolyze ATP when bound to glass. Instead, nucleotide triphosphate may be needed only to achieve a weak binding state of the motor with the microtubule. This is consistent with models for motor function that are based on diffusional movement of the motor protein (Vale and Oosawa, 1990; Córdova et al., 1992). Such models require ATP hydrolysis to confer directionality to the movement, not for the movement itself.

The diffusional movement observed for microtubules bound to MC1 on glass is not dependent on the addition of vanadate. In addition, vanadate does not affect the ability of MC1 to hydrolyze $\mathrm{Mg}^{2+}$-ATP in in vitro assays (Table 1). These results suggest either that vanadate does not bind, or does not affect the ability of $\mathrm{Mg}^{2+}$-ATP to bind, to MC1.

The diffusional movement of bound microtubules suggests that the truncated motor on the glass surface is in a conformation in which it can bind only weakly to microtubules in the presence of $\mathrm{Mg}^{2+}$-ATP. A weak binding state characterized by diffusional movement may be intrinsic to the ncd motor protein, or it may arise as a consequence of a steric factor associated with attachment of the truncated motor to the glass. Although we cannot distinguish between these possibilities, the ability to bind weakly and support diffusional movement in a nucleotide-sensitive fashion is consistent with the idea that the motor retains at least part of its normal function on the glass surface, i.e. the ability to bind nucleotide and microtubules. As a consequence, either of the truncation or the attachment of the truncated motor to glass, the motor appears to be locked into a conformational state in which it binds weakly to microtubules in the presence of $\mathrm{Mg}^{2+}$-ATP and supports diffusional movement of bound microtubules. This state may represent a weak binding state of the motor that is a mechanochemical intermediate of the ATP hydrolysis cycle, or force cycle, of the protein.

Bacterially expressed proteins corresponding to the $\mathrm{N}$ terminal 182 or 204 amino acids of the "tail" of ncd can bind to, and crosslink, microtubules (Chandra et al., 1993). The microtubule crosslinking activity corresponds to a highly basic, proline-rich region that is missing in $\mathrm{MC} 1$ (Fig. 1) and may be needed for strong binding of the motor to the microtubule for energy transduction during or after ATP hydrolysis. Alternatively, the $\mathrm{N}$ terminus of ncd may act as a "ratchet" to produce directional force from the thermally driven movement of the motor domain and function as part of the energy-transducing mechanism (Vale and Oosawa, 1990). The observation that a glutathione Stransferase/MC1 fusion protein can support directional gliding of microtubules (Chandra et al., 1993) provides evidence that a different protein can substitute for the ncd $\mathrm{N}$ terminus in allowing the motor domain to produce directional translocation when bound to a glass surface. The 26 $\mathrm{kDa}$ glutathione S-transferase domain may bind MC1 to the surface in the same manner as the $\mathrm{N}$ terminus, overcoming steric effects that may occur when $\mathrm{MC} 1$ is directly attached to glass.

Nevertheless, there are two remarkable aspects of the weak binding of microtubules to $\mathrm{MC} 1$ on glass. One is that the diffusional motion is constrained to the longitudinal axis of the microtubule, and the second is that the binding is weak. If the weak binding of MC1 to microtubules in our motility assays occurred in a random fashion, we would expect both lateral and longitudinal diffusional movement. The observation of only longitudinal diffusion indicates that MC1 retains the ability to move longitudinally on the microtubule, like the ncd motor. Two models have been proposed to explain the diffusional movement of the $\beta$-IC dynein in the presence of vanadate (Córdova et al., 1991; Tawada and Sekimoto, 1991). The first model proposes that the motor moves in an electrostatic groove on the microtubule, such that lateral movement is prevented sterically and longitudinal movement is hindered by frictional drag. The second, the equilibrium binding hypothesis, explains the constraint on diffusional movement by rapid cycles of association/dissociation of the motor. The electrostatic groove model predicts that the mean square longitudinal displacement will be inversely dependent on microtubule length, while the equilibrium binding model predicts an inverse length square dependence (Córdova et al., 1991; Tawada and Sekimoto, 1991). Unfortunately, there is too much scatter in the data in Fig. 6 to discriminate between the predictions of these two models, and only a linear regression line through the data is shown.

The diffusional movement that we observe for the MC1 protein in vitro may be important in the in vivo function of the claret motor. In addition to the minus end-directed translocation of the motor on microtubules, truncated forms of the protein may bind to and diffuse along spindle microtubules. Alternatively, proteins associated with the ncd $\mathrm{N}$ terminus, such as light chains, may bind to the motor, preventing the association of the $\mathrm{N}$ terminus with microtubules and allowing diffusional movement of the motor on microtubules. Such diffusional movement may be important in ncd motor function in meiotic and mitotic cells (Hatsumi and Endow, 1992a,b; Endow, 1992).

Finally, the diffusional movement of $\mathrm{MC} 1$ revealed in our studies emphasizes that microtubule motors perform dual functions: binding to microtubules and directional translocation on microtubules. Other members of the kinesin family of microtubule motor proteins may also possess the ability to bind microtubules and support onedimensional diffusional movement, providing a mechanism for motor proteins to form stable attachments to the microtubule and allowing other forces to drive movement along the microtubule. This would help to explain aspects of intracellular movement now thought to be mediated by motor proteins, such as kinetochore attachment and movement of chromosomes on spindle microtubules (Mitchison, 1989).

We thank R. Vale and R. Cross for helpful discussions, J. Davis 
for advice and help with Fig. 2, P. Casey for advice regarding the ATP hydrolysis experiments, V. Skeen for purified tubulin and taxol-stabilized microtubules, and for carrying out the $\mathrm{Mg}^{2+}-\mathrm{GTP}$ depletion experiments, K. Sawin for a generous gift of anti-HIPYR antibody, and N. Gliksman and members of the Salmon laboratory for help with the VE-DIC microscopy. Taxol was supplied by the Drug Synthesis \& Chemistry Branch, Division of Cancer Treatment, National Cancer Institute. Supported by grants from the USPHS to S.A.E. and to E.D.S.

\section{REFERENCES}

Berg, H. C. (1983). Random Walks in Biology. Princeton: Princeton University Press.

Chandra, R., Salmon, E. D., Erickson, H. P., Lockhart, A. and Endow, S. A. (1993). Functional and structural characterization of the ncd microtubule motor protein. J. Biol. Chem. (in press).

Cohn, S. A., Ingold, A. L. and Scholey, J. M. (1987). Correlation between the ATPase and microtubule translocating activities of sea urchin egg kinesin. Nature 328, 160-163.

Cole, D. G., Cande, W. Z., Baskin, R. J., Skoufias, D. A., Hogan, C. J. and Scholey, J. M. (1992). Isolation of a sea urchin egg kinesin-related protein using peptide antibodies. J. Cell Sci. 101, 291-301.

Córdova, N. J., Ermentrout, B. and Oster, G. F. (1992). Dynamics of single-motor molecules: the thermal ratchet model. Proc. Nat. Acad. Sci. USA 89, 339-343.

Córdova, N. J., Vale, R. D. and Oster, G. F. (1991). Dynein-microtubule interactions. In Biologically Inspired Physics (ed. L. Peliti), pp. 207-215. New York: Plenum Press.

Endow, S. A. (1991). The emerging kinesin family of microtubule motor proteins. Trends Biochem. Sci. 16, 221-225.

Endow, S. A. (1992). Meiotic chromosome distribution in Drosophila oocytes: Roles of two kinesin-related proteins. Chromosoma 102, 1-8.

Endow, S. A., Henikoff, S. and Soler-Niedziela, L. (1990). Mediation of meiotic and early mitotic chromosome segregation in Drosophila by a protein related to kinesin. Nature 345, 81-83.

Endow, S. A. and Titus, M. A. (1992). Genetic approaches to molecular motors. Ann. Rev. Cell Biol. 8, 29-66.

Goldstein, L. S. B. (1991). The kinesin superfamily: tails of functional redundancy. Trends in Cell Biology 1, 93-98.

Hatsumi, M. and Endow, S. A. (1992a). Mutants of the microtubule motor protein, nonclaret disjunctional, affect spindle structure and chromosome movement in meiosis and mitosis. J. Cell Sci.101, 547-559.

Hatsumi, M. and Endow, S. A. (1992b). The Drosophila ncd microtubule motor protein is spindle-associated in meiotic and mitotic cells. J. Cell Sci. 103, 1013-1020.

Higashijima, T., Ferguson, K. M., Smigel, M. D. and Gilman, A. G. (1987). The effect of GTP and $\mathrm{Mg}^{2+}$ on the GTPase activity and the fluorescent properties of $\mathrm{G}^{*}{ }^{*}$. J. Biol.Chem. 262, 757-761.

McDonald, H. B. and Goldstein, L. S. B. (1990). Identification and characterization of a gene encoding a kinesin-like protein in Drosophila. Cell 61, 991-1000.

McDonald, H. B., Stewart, R. J. and Goldstein, L. S. B. (1990). The kinesin-like $n c d$ protein of Drosophila is a minus-end directed microtubule motor. Cell 63, 1159-1165.

Mitchison, T. J. (1989). Chromosome alignment at mitotic metaphase: balanced forces or smart kinetochores? In Cell Movement, Volume 2: Kinesin, Dynein, and Microtubule Dynamics (ed. F. D. Warner and J. R. McIntosh), pp. 421-430. New York: Alan R. Liss, Inc.

Qian, H., Sheetz, M. P. and Elson, E. L. (1991). Single particle tracking. Analysis of diffusion and flow in two-dimensions. Biophys. J. 60, 910 921.

Sanger, F., Nicklen, S. and Coulson, A. R. (1977). DNA sequencing with chain-terminating inhibitors. Proc. Nat. Acad. Sci. USA 74, 5463-5467.

Sawin, K. E., Mitchison, T. J. and Wordeman, L. G. (1992). Evidence for kinesin-related proteins in the mitotic apparatus using peptide antibodies. J. Cell Sci. 101, 303-313

Studier, F. W., Rosenberg, A. H., Dunn, J. J. and Dubendorff, J. W. (1990). Use of T7 RNA polymerase to direct expression of cloned genes. Meth. Enzym. 185, 60-89.

Tawada, K. and Sekimoto, K. (1991). Protein friction exerted by motor enzymes through weak-binding interaction. J. Theor. Biol. 150, 193-200.

Vale, R. D. and Oosawa, F. (1990). Protein motors and Maxwell's demons: does mechanochemical transduction involve a thermal ratchet? Adv. Biophys. 26, 97-134

Vale, R. D., Soll, D. R. and Gibbons, I. R. (1989). One-dimensional diffusion of microtubules bound to flagellar dynein. Cell 5, 915-925.

Wagner, M. C., Pfister, K. K., Bloom, G. S. and Brady, S. T. (1989). Copurification of kinesin polypeptides with microtubule-stimulated $\mathrm{Mg}$ ATPase activity and kinetic analysis of enzymatic properties. Cell Motil. Cytoskel. 12, 195-215.

Walker, R. A., O'Brien, E. T., Pryer, N. K., Soboeiro, M. F., Voter, W. A., Erickson, H. P. and Salmon, E. D. (1988). Dynamic instability of individual microtubules analyzed by video light microscopy: rate constants and transition frequencies. J. Cell Biol. 107, 1437-1448.

Walker, R. A., Salmon, E. D. and Endow, S. A. (1990). The Drosophila claret segregation protein is a minus-end directed motor molecule. Nature 347, 780-782.

Yamamoto, A. H., Komma, D. J., Shaffer, C. D., Pirrotta, V. and Endow, S. A. (1989). The claret locus in Drosophila encodes products 
required for eyecolor and for meiotic chromosome segregation. EMBO J. 8, 3543-3552.

Yang, J. T., Layman, R. A. and Goldstein, L. S. B. (1989). A threedomain structure of kinesin heavy chain revealed by DNA sequence and microtubule binding analyses. Cell, 56, 879-889.

(Received 6 October 1992 - Accepted 24 November 1992) 